\title{
Information System Quality and Its Impact on Individual Users' Benefit: Analyzing the Role of Knowledge Enablers
}

\author{
Iman Sudirman' ${ }^{1}$ Rajesri Govindaraju ${ }^{1 *}$, Andara Arie Pratiwi ${ }^{1}$
}

\begin{abstract}
With increasing competitive pressures, companies are trying to improve the quality of their processes and the work quality employee. This fact has triggered the companies to improve their information systems. Having made some investments in IT systems, those companies look for ways to gain benefits from their investments. The benefit from IS investment arise when the use of information system (IS) provides some positive impact to the organisation in terms of business impacts and individual impacts. Thus, investigating IS impact for individual user's performance is very important. This study explores the effect of IS quality on individual benefits. The influence of six moderating variables related to knowledge enablers on the impact of IS quality on individual benefits was studied. The six moderating variables are: collaboration, trust, learning, centralisation, expertise, and formalisation. Data were collected using questionnaires distributed at two big private companies in Indonesia. Data processing was done with the help of SPSS software. After factor analysis, IS quality was split into two variables: Information quality and System and service quality. The study found that both variables influence the perceived individual benefits significantly. The influence of information quality on individual benefit is positively moderated by expertise, learning, centralisation and formalisation. Finally, the influence of system and service quality on individual benefit is positively moderated by expertise and formalization.
\end{abstract}

Keywords: Information systems, IS quality, individual benefits, knowledge enablers, information quality, system and service quality.

\section{Introduction}

With increasing competitive pressures, companies are trying to improve the quality of their processes and the work quality of their employees. This fact has triggered the companies to improve their information systems. Information system (IS) as an asset that is a result of company's IT investment is expected to bring benefits to the company (Croteau and Bergeron, [1]). The benefit from IS investment arise when the use of information system (IS) provides some positive impact to the organisation in terms of business impacts and individual impacts.

Palvia et al. [2] suggested that certain quality of information system can contribute to the delivery of expected benefits. Therefore, most previous studies in IS success (e.g. DeLone and McLean [3]; Seddon [4]; Gable et al. [5]) address the influence of differents aspects of IS quality on the benefits. Most of earlier studies on IS success found that a high quality IS has positive organisational impacts (e.g. Brynjolfsson and Hitt, [6]; Mukherjee, [7]).

\footnotetext{
${ }^{1}$ Faculty of Industrial Technologi, Industrial Engineering Department, Institut Teknologi Bandung. Лl. Ganesha 10, Bandung 40132, Indonesia. Email: imansudirman_itb@yahoo.com; rajesri_g@ti.itb.ac.id; andara_arie@hotmail.com

* Corresponding author
}

Igbaria and Tan [8] studied the relationships between IS and user performance by investigating relationships among several variables including system use, system quality, information quality, user satisfaction and individual performance. They found that system quality, information quality and system use affect user performance positively. Studying the IS and its relation with decision making in organisations, Barki and Huff [9] found that IS quality has a significant impact on user performance, decision quality and tame taken to make decisions.

Chan et al. [10] examined the influence of some factors on user performance. These factors include system, data model, tasks characteristics and user characteristics. They found that the factors affect user performance positively. Recently, Stone et al. [11] have investigated the impacts of IS on individual performance in a more comprehensive model linking information quality, system quality, and tasks performed. The results indicate that information quality and system quality affect tasks performed by individual.

Though the relationships between IS quality and the benefits on individual as well as organisation levels had been described by earlier studies (e.g. DeLone and McLean, [3]; Chan et al. [10]; Stone et al. [11]), limitted studies have provided an analysis of organisation's condition that explain the relationship 
between IS quality and the benefits perceived by individual users. Therefore studying the way organisation's situation can influence the effect of IS quality on user benefits is considered valuable, for academics as well as practitioners.

IS usage in organisations is meant to support the development of individual users. The consistent development of individual in organisations is influenced by organisational mechanisms in generating knowledge within the organisation. Lee and Choi [12] divided the organisational mechanism in the context of knowledge enabler into six factors: collaboration level, trust level, learning level, individual authority/centralisation level, individual understanding/expertise level, and formalisation in level of the company.The objective of this study is to investigate the impact of IS quality on individual benefits and analyse the influence of knowledge enablers on the effect of IS quality on individual IS benefits. This study contributes to develop a better understanding regarding the way some organisational factors related to knowledge enablers affect the realisation of benefits from the use of IS. This understanding is useful to optimize the utilization of IS in organisations.

\section{Methods}

\section{Benefits from IS usage}

According to Shang and Seddon [13], the benefits of IS are divided into five dimensions: operational, managerial, strategic, infrastructural, and organisational. Operational benefits are felt in the day-to-day activities such as cost reduction, cycle time reduction, productivity improvement, quality improvement, and improved customer service. Managerial benefits are indicated by improved resource management, improved quality of planning and decisionmaking, and improved performance in various divisions within the organisation. Strategic benefits are gained from information systems contributions in achieving competitive advantage of business enterprises in terms of cost, innovation, product differentiation, organisation growth, and its relationship with alliance (Porter [14]). Infrastructural benefits are demonstrated by the availability of support in business flexibility to changes the future, lower the cost of information technology in each business unit, and increase the speed as well as the economic value of new applications implementation in the future.

Organisational benefits arise when the use of information systems provides some benefits to the organisation in terms of business focus, consistency, and learning by its organisational members (Roos et al. [15]). These organisational benefits are seen in the development of employee knowledge and increased communication among employees. Individual benefits which are derived from the achievement of the organisational benefits can be measured by the facts that individuals learn and develop their skills, increase authority of individual at work, improve common understanding of goals of organisation, change work focus, and improve the quality and satisfaction of individual moral, because information system provides transparency and minimizes the possibility of cheating, as well as provides services that make their jobs easier (Roos et al. [15]).

\section{Research Model and Hypotheses}

\section{Information System (IS) Quality and Indivi- dual Benefits}

There is not a common definition used to describe the quality of IS. This is attributed to the fact that different stakeholders may view IS quality differently. Top management who usually sponsors the IS implementation often view IS quality in terms of return on ivestment and other business or organisation impacts. IS quality can also be judged by the operational benefits of the system and its support for decision making. For end users, ease of use (usability) and the capability of IS to enhance users' personal effectiveness are very important aspects of IS quality.

Intuitively, many people presume that the highquality IS will bring benefits to the implementing organisations. The influence of differents aspects of IS quality on the benefits had been addressed by previous studies (e.g. DeLone and McLean, [3]; Seddon, [4]; Gable et al. [5]). DeLone and McLean, [3] identified six factors for the success of information systems, namely system quality, information quality, system use, user satisfaction, individual impact and organisational impact. In addition, Seddon [4] in his extension of the work of DeLone and McLean [3]. Later on, the impacts of information systems on individual performance were studied by Stone et al. [11]. The results of their study show that the measures of the quality of information and system quality affect the tasks performed by the individual users.

Palvia et al. [2] interpreted IS quality as distinct features and characteristics of a system that contribute to the delivery of expected benefits and the satisfaction of perceived needs. Referring to Palvia et al. [2], IS quality is in this study defined as the characteristics of IS that describe how well the IS 
supports the individual users in executing business processes in an organisation. Adapted from the operationalisation proposed by DeLone and McLean [3], IS quality is in this study measured by information quality, ease of use of the technology, system quality, support provided by internal IS, and user satisfaction (DeLone and McLean, [3]). The influence of IS quality as one construct which reflects the capability of IS in supporting the organisation's business processes, on the benefits achieved by individual users, will be investigated.

H1: IS quality has a positive influence on individual benefits.

\section{The Influence Knowledge Enabler}

In this study, the influence of organisational mechanisms in the context of knowledge enabler, on the relationship between IS quality and individual benefits, will be explained. The organisational mechanisms is seen as the management of organisational culture, organisational structure, and human factors. Lee and Choi [12] divides the organisational mechanism in to six factors knowledge enabler: collaboration level, trust level, learning level, individual authority/centralisation level, individual understanding/expertise level, and formalisation.

Organisational culture is the most important factor for individual development success (Davenport et al., [3]). Culture itself is not only defined as the value produced by knowledge, but also how knowledge should be kept within the organisation to support innovation growing needs (Long [17]). Organisations should provide appropriate culture that can facilitate people to create and share knowledge within the organisation (Holsapple and Joshi [18]). Related to the organisational culture, this study focuses on studying the influence of collaboration, trust, and learning, on the realisation of individual benefits. Structure within organisations can lead to the development of individuals. Ichijo et al. [19] stated that company must consistently maintain its structure so that the knowledge in it can be used. This study involves two key factors related to organisational structure, namely individual authority (centralisation) and formalisation within the company (Menon et al. [20]). Human, as the heart of the creation of knowledge within the organisation (Bharadwaj, [21]), is the one who create and share knowledge. Therefore managing human so they are willing to create and share knowledge with each other is a very important thing to do (O'Dell and Grayson, [22]). Knowledge and competence of human (people) in the organisation is addressed as expertise.

\section{Collaboration}

Collaboration can be defined as the degree to which individuals in the group actively assist each other in completing the work (Hurley and Hult, [23]). Culture influences the creation of collaborative knowledge by improving the exchange of information (von Krogh, [24]). Exchange of information and knowledge among members of the organisation is a prerequisite for the creation of knowledge. Collaboration in relation to the use of information systems is needed to determine how to provide an effective social process. The higher the level of collaboration in an organisation, the higher the level of knowledge formation, which in turn increases the benefits gained by individual members of the organisation.

$\mathrm{H} 2$ : Collaboration influences positively the effect of IS quality on individual benefits

\section{Trust}

Trust is defined as the extent to which a person believes that other people can meet his/her expectations (Shaw [25]). Trust is the level of belief in the behavior, intent, and capabilities of others (Kreitner and Kinicki [26]). Trust can foster openness, honesty, and influencing the exchange of knowledge within the organisation (Nelson and Cooprider [27]). When the relationship between individuals in the organisation has a high level of trust, they will be more willing to participate in the exchange of knowledge (Nahapiet and Ghoshal [28]). The higher the level of trust in the organisation, the higher the level of knowledge formation, which in turn increases the benefit gained by individual members of the organisation.

H3: Trust influences positively the effect of IS quality on individual benefits

\section{Learning}

Learning can be defined as the level of support for the organisation's members to learn and grow within the organisation (Hurley and Hult [23]). To be successful in the creation of knowledge, organisations must develop a strong learning culture and provides a variety of facilities such as education, training, and mentoring (Quinn et al. [29]). Attention on the learning process can facilitate the organisation to gain new knowledge (Damanpour [30]). Through the learning process, the organisation helps its members to take an active role in the creation of knowledge. The time spent on studying is positively associated with the amount of knowledge gained (Kanevsky and Housel [31]). The higher the level of support for learning, the higher the level of knowledge formation, which in turn increases the benefit gained by individual members of the organisation. 
H4: Learning influences positively the effect of IS quality on individual benefits

\section{Expertise}

Expertise can be defined as the level of skill and understanding owned by individuals related to their jobs and other jobs in a company (Leonard-Barton [32]). Expertise that is owned by a person or a system can make the person or the system provides the desired results (Madhavan and Anol [33]). Individuals who have a high level of expertise is very valuable in creating knowledge because they are able to integrate various knowledge they gain (Leonard-Barton [32]). The higher a person's level of expertise, the higher the level of knowledge formation, which in turn increases the benefit gained by individual members of the organisation.

H5: Expertise influences positively the effect of IS quality on individual benefits

\section{Centralisation}

Centralisation can be defined as the degree of authority and control of a person or a particular group within the organisation regarding the decision he made (Caruana et al. [34]). Decision-making which is concentrated in one person or one group will reduce creative solutions. The distribution of the power in decision making will facilitate the creation of an atmosphere of spontanity, brave in doing experiments, and having freedom of expression and opinion, which is key to the creation of knowledge (Graham and Gibson [35]). Centralized organisation structure will hinder communication between departments and reduce the frequency of exchange of ideas because they have to pass through the bureaucracy (Woodman et al. [36]). Centralisation also can cause distortions and unsustainable ideas (Stonehouse and Pemberton [37]). Decentralized organisational structure has been shown to create an environment in which members are willing to participate in the process of knowledge creation in a more spontaneous way (Hopper [38]). Thus, a smooth flow of the ideas is necessary if the usage of IS is expected to facilitate the creation of knowledge that will in turn help individuals in gaining benefits from IS usage. In other words, the higher the centralisation in a company, the lower the level of knowledge creation, which in turn lowers the benefit gained by individual members of the organisation.

H6: Centralisation influences negatively the effect of IS quality on individual benefits

\section{Formalisation}

Formalisation is the degree to which all things related to the work clearly regulated by formal rules, legal standards, and procedures (Holsapple and Joshi [14]). Flexibility in performing works is important for the creation of knowledge in an organisation (Ichijo et al. [19]). New ideas will be inhibited when the formal rules dominate the company. Flexibility can accommodate a better way to resolve a problem (Graham and Gibson [35]), thus increasing the flexibility in the organisational structure can enhance the creation of knowledge. Openness in communication and interaction can also encourage the creation of knowledge (Bennett and Gabriel [39]). Fewer formal structure tends to allow organisation members to communicate and interact with each other for the creation of knowledge (Jarvenpaa and Staples [40]). Thus, a high degree of formalisation in a company will lead to a low level of knowledge creation, which in turn lowers the benefit gained by individual members of the organisation.

H7: Formalisation influences negatively the effect of IS quality on individual benefits

The conceptual model developed in this study is presented in Figure 1.

\section{Data Collection}

The developed model was further operationalised and a questionnaire set was prepared for the data collection purpose. The questionnare set is presented in Appendix 1. The respondents are employess working in two companies: TNT and South Pacific Viscose (SPV). The criteria used to select the respondents are: having been working for at least 3 years and having been using the IS applications for at least two years. From 150 distributed questionnaires, 98 responses were collected. The profiles of respondents can be seen in Table 1 and Table 2 .

Most of the collected samples were obtained from questionnaires directly distributed to the intended respondents. Some others were distributed via email. The average of working experience also descrybes that the respondents who filled out questionnaires have a good understanding of their work environment, so the sample are representative enough to estimate the research parameters.

Table 1. Profile of the respondent based on company

\begin{tabular}{lcc}
\hline \multicolumn{1}{c}{ Company } & \multicolumn{2}{c}{ Number of respondent } \\
& Distributed & Returned \\
\hline South Pacific Viscose & 100 & 60 \\
(Purwakarta) & 50 & 38 \\
TNT (Jakarta) & 150 & 98 \\
\hline Total & \\
\hline
\end{tabular}


Table 2. Profile of the respondent based on working experience

\begin{tabular}{lc}
\hline \multicolumn{1}{c}{ Company } & $\begin{array}{c}\text { Average working } \\
\text { experience }\end{array}$ \\
\hline South Pacific Viscose (Purwakarta) & 13.47 years \\
TNT (Jakarta) & 5.84 years \\
\hline
\end{tabular}

Table 3. Results of reliability testing

\begin{tabular}{lc}
\hline \multicolumn{1}{c}{ Variabel } & $\begin{array}{c}\text { Koefisien Alpha } \\
\text { Cronbach's }\end{array}$ \\
\hline Individual benefit & 0.971 \\
IS quality & 0.935 \\
Collaboration & 0.802 \\
Trust & 0.892 \\
Learning & 0.607 \\
Expertise & 0.909 \\
Centralisation & 0.894 \\
Formalisation & 0.803 \\
\hline
\end{tabular}

\section{Data Processing}

Data processing was done to perform reliability testing, validity testing (using exploratory factor ana lysis) and hypothesis testing (using mulitple regression technique). These overall processing techniques were performed with the support of SPSS 12.0.2 software. Reliability of all the constructs was tested using Cronbach alpha's values. Cronbach alpha value $>0.6$ indicates that the constructs are reliable for use in subsequent analysis. Results of reliability analysis for independent variable, moderator variables, and the dependent variable are presented in Table 3. The results show that all the constructs are realiable.

For validity testing, exploratory factor analysis was applied to all the constructs. Based on the results, a number of items (indicators for the construct) were deleted. Special for "IS quality" construct, as can be seen in Table 4, the results show that the construct should be devided into two factors as follow:

Factor 1 contains measures related to information quality and user satisfaction, and shortly named "Information quality".

Tabel 4. Rotated component matrix for IS quality construct

\begin{tabular}{lcc}
\hline & \multicolumn{2}{c}{ Component } \\
\cline { 2 - 3 } & 1 & 2 \\
\hline AI4 & .674 & \\
AI5 & .938 & \\
AI6 & .935 & \\
AI7 & .926 & .760 \\
AI1 & & .696 \\
AI2 & .535 & .561 \\
AI3 & .724 & .869 \\
AI8 & & \\
AI9 & & \\
\hline
\end{tabular}

Factor 1 consists of the following five measures: (AI3) Information system application that I use in my work provides precisely the information I need. (AI4) Information systems application that I use provides enough information for me to do my work. (AI5) The information system provides data to speed up decision-making in my work. (AI6) Information provided by the system makes executing my job much easier. (AI7) I feel the information system is useful for my job.

Factor 2 contains measures related to system quality and service quality, and shortly named "System \& service quality". Factor 2 consists of the following four measures: (AI1) The IT personnel assigned to provide support for the use and maintenance of information systems that I use has a very good technical ability. (AI2) information system that I use is very user friendly and easy to use. (AI8) I am satisfied with the functionalities provided in the IS application. (AI9) When there is a problem in the IS application that I use, I can easily get help from the existing IT staffs

Regarding the influence of information quality on individual performance, Redman [41] argued that poor information quality brings negative impacts on organisations at operational, tactical, and strategic levels. Employees will get less job satisfaction because of inaccurate or incomplete information. The quality of decision making will also be affected by irrelevant information. Selection and execution of a sound business strategy will become difficult because of inaccurate or delayed information. On the other hand, high information quality in terms of information content can lead to a positive impact on individual performance. Further, Stone et al. [11] found that the quality of information affects the tasks performed by the user.

H1a: Information quality has a positive influence on individual benefits

Regarding the influence of system and service quality on individual performance, a number of researchers found that system quality and service quality have a positive impact on individual performance. A well-developed and implemented system is a necessary condition to deriving benefits from the use of IS. Wixom and Watson [42] found that system quality in the case of data warehousing has been shown to be positively associated with perceived benefits in terms of individual productivity and ease of decision making. IS departments act as service units for various users in the organisation, and organisational success depends on how well the IS services are delivered. Kettinger and Lee [43] found that perceived service quality has a positive 
influence on user satisfaction with the information services function. Gelderman [44] found that high level of user satisfaction will lead to a high usage of IS which will in turn increase the impact of IS on individual users.

H1b: System \& service quality has a positive influence on individual benefits

The influence of six moderating variables on the relationships highlighted in $\mathrm{H} 1 \mathrm{a}$ and $\mathrm{H} 1 \mathrm{~b}$ are analysed. The research model was then revised based on the result of the factor analysis, and the revised model is presented in Figure 2.

\section{Results and Discussion}

The results of hypotheses testing using Ridge regression are presented in Table 5 . As can be seen in Table 5, this study found that both information quality and system \& service quality have significant influence on the perceived benefits by individual users. The influence of information quality on individual impact is positively moderated by expertise, learning, centralisation and formalisation.

Description of the influence of each moderating variables is as follow:

The influence of expertise means that with the increasing levels of expertise, the impact of good information quality on users' individual benefit will increase.

The influence of learning means that with the increasing levels of learning process take place in the organisation, the impact of good information quality on users' individual benefit will increase.

The influence of centralisation means that with the higher levels of centralisation of decision making and tasks in the organisation, the impact of good information quality on users' individual benefit will increase.

The influence of formalisation means that with the higher levels of formalisation in the ways things are executed in the organisation, the impact of good information quality on users' individual benefit will increase.

For the influence of system and service quality toward the user individual benefit, the moderating variables that are proven to be influential are expertise and formalisation. With the increasing levels of individual knowledge and skill (expertise), the impact of good service quality on users' individual benefit will increase. Finally, with higher
Tabel 5. Recapitulation of data processing results

\begin{tabular}{|c|c|}
\hline Influencing variable(s) & Conclusion \\
\hline Information quality (AI_1)* & Accepted \\
\hline System and service quality (AI_2) & Accepted \\
\hline $\begin{array}{l}\text { Information quality X Collaboration } \\
\text { (AI1_CO) }\end{array}$ & Rejected \\
\hline Information quality X Trust (AI1_TR) & Rejected \\
\hline Information quality X Learning (AII_LN) ${ }^{*}$ & Accepted \\
\hline $\begin{array}{l}\text { Information quality X Expertise } \\
\text { (AI1_EXP)* }\end{array}$ & Accepted \\
\hline $\begin{array}{l}\text { Information quality X Centralisation } \\
\text { (AI1_CE)* }\end{array}$ & Accepted \\
\hline $\begin{array}{l}\text { Information quality X Formalisation } \\
\text { (AI1_FO)* }\end{array}$ & Accepted \\
\hline $\begin{array}{l}\text { System \& service quality X Collaboration } \\
\text { (AI2_CO) }\end{array}$ & Rejected \\
\hline Service \& service quality X Trust (AI2_TR) & Rejected \\
\hline $\begin{array}{l}\text { System \& service quality X Learning } \\
\text { (AI2_LN) }\end{array}$ & Rejected \\
\hline $\begin{array}{l}\text { System \& service quality X Expertise } \\
\text { (AI2_EXP)* }\end{array}$ & Accepted \\
\hline $\begin{array}{l}\text { Service \& service quality X Centralisation } \\
\text { (AI2_CE) }\end{array}$ & Rejected \\
\hline $\begin{array}{l}\text { Service \& service quality X Formalisation } \\
\text { (AI2_FO)* }\end{array}$ & Accepted \\
\hline
\end{tabular}

level of formalisation in the organisation, the impact of good service quality on users' individual benefit will increase.

In order to increase the benefits gained by individual users, it is found that the quality of information provided by IS plays an important role. It is important that users get sufficient amount of precise information that helps them in making decision.

Further, it is very important that the information provided by the system can help the users to execute their task faster. Besides, service provided by internal IT function also plays an important role in creating benefits on the individual level. For managers, this study also suggested that it is necessary to facilitate trust among their organisational members, create a better formal mechanism to support the use of IS, and support the decentralisation of power, if their organisations want to facilitate the conversion from IS usage into the benefit realisation by the individual members.

\section{Conclusion}

In this study, a model had been developed and tested, to analyse the impact of information system quality on benefits gained by individual users. In this study, the moderating roles of six knowledge enablers including collaboration, trust, learning, expertise, centralisation, and formalisation were also analysed. IS quality was splitted into two variables: 
information quality and system \& service quality. The study found that both information quality and system \& service quality have significant influence on the benefits perceived by individual users. Further, the influence of information quality on individual benefits is positively moderated by expertise, learning, centralisation and formalisation. The influence of system \& service quality on individual benefits is positively moderated by expertise and formalisation. This study has contributed in creating a better understanding regarding the organisational mechanisms, especially mechanisms that are related to knowledge enablers, that affect the realisation of benefits from the use of IS by individual users.

As can be seen in 4 , the coefficient of determination $\left(\mathrm{R}^{2}\right)$ is 0.761 indicating that $76.1 \%$ benefits gained by individual users can be explained by the two independent variables and six moderating variables while $23.9 \%$ is explained by other factors.Therefore further research could examine the influence of other factors that are not included in the research model. Besides, data sample used in this study came from two private companies. Further research can use samples from a more diversed companies so that the result will have a more generalization power.

\section{References}

1. Croteau, A., and Bergeron, F., An Information Technology Trilogy: Business Strategy, Technological Deployment and Organisational Performance, The Journal of Strategic Information Systems, 2001, pp. 77-99.

2. Palvia, S.C., Sharma, R.S., and Conrath, D.W., A Socio-technical Framework for Quality Assessment of Computer Information Systems, Industrial Management \& Data Systems, 101(5), 2001, pp. 237-251.

3. DeLone, W., and McLean, E., Information System Success: The Quest for the Dependent Variable, Journal of Information System Research, 3(1), 1992, pp. 60-95.

4. Seddon, P.B., A Respecification and Extension of the DeLone and McLean Model of IS Success, Information Systems Research, 8(3), 1997, pp. 240-253.

5. Gable, G.G., Sedera, D., and Chan, T., Enterprise Systems Success: A Measurement Model, Proceedings of the 24th. ICIS, 2003, pp.576-591.

6. Brynjolfsson, E. and Hitt, L., Paradox Lost? Firm-level Evidence on the Returns to Information Systems Spending, Management Science, 42(4), 1996, pp. 541-558.

7. Mukherjee, K., Productivity Growth in Large US Commercial Banks: The Initial Post Regulation Experience, Journal of Banking and Finance, 25(5), 2001, p. 913.
8. Igbaria, M., and Tan, M., The Consequences of the Information Technology Acceptance on Subsequent Individual Performance, Information \& Management, 32, 1997, pp. 113-121.

9. Barki, H., and Huff, S.L., Change, Attitude to Change, and Decision Support System Success, Information \& Management, 9(5), 1985, pp. 261268.

10. Chan, C., Siau, K., and Wei, K., The Effect of Data Model, System and Task Characteristics on User Query Performance: An Empirical Study. The DATA BASE for Advances in Information Systems, 29(1), 1998, pp.105-120.

11. Stone, R.W., Good, D.J., and Baker-Eveleth, L., The Impact of Information Technology on Individual and Firm Marketing Performance, Behaviour \& Information Technology, 26(6), 2007, pp. 465-482.

12. Lee, H., and Choi, B., Knowledge Management Enablers, Process, and Organisational Performance: An Integrative View and Empirical Examination, Journal of Management Information Systems, 2003, pp. 179-228.

13. Shang, S., and Seddon, P., Assesing and Managing the Benefits of Enterprise System: The Business Manager's Perspective, Journal of Information System, 12, 2002, pp. 271-299.

14. Porter, M., Competitive Advantage, Free Press, New York, 1985.

15. Roos, J., Roos, G., Edvinsson, L., and Dragonetti, N., Intellectual Capital: Navigating in the New Business Landscape, New York University Press, New York, 1997.

16. Davenport, T., Long, D., and Beers, M., Successful Knowledge Management Project, Sloan Management Review, 1998.

17. Long, D., Building the Knowledge Based Organisation: How Culture Drives Knowledge Behaviours, Ernst \& Young LLP, Cambridge, 1997.

18. Holsapple, C., and Joshi, K., Organisational Knowledge Resources, Journal of Decision Support System, 2001.

19. Ichijo, K., Krogh, G., and Nonaka, I., Knowledge Enablers, Knowing Firms: Understanding, Managing and Measuring Knowledge, Sage Publications, London, 1998.

20. Menon, N., Lee, B., and Eldenberg, L., Information Technology Productivity in the Health Care Industry, Proceedings of the Seventeenth International, 1996, pp. 477.

21. Bharadwaj, A., A Resource-based Perspective on Information Technology Capability, Journal of MIS Quarterly, 24(1), 2000, pp. 169-196.

22. O'Dell, C., and Grayson, J., Knowledge Transfer: Discover Your Value Proposition, Strategy and Leadership, 1999.

23. Hurley, R., and Hult, T., Innovation, Market Orientation and Organizational Learning: An 
Integration and Empirical Examination, Journal of Marketing, 62, 1998, pp. 42-54.

24. Von Krogh, G., Care in the Knowledge Creation. California Management Review, 40(3), 1998, pp. 133.

25. Shaw, F.B., Trust in Balance, San Francisco: Jossey-Bass, 1997.

26. Kreitner, R., and Kinicki, A., Organizational Behavior, Irwin, Boston, MA, 1992.

27. Nelson, K., and Cooprider, J., The Contribution of Shared Knowledge to IS Group Performance, MIS Quarterly, 20(4), 1996, pp. 409-432.

28. Nahapiet, J., and Ghoshal, S., Social Capital, Intellectual Capital, and the Organizational Advantage, Academy of Management Review, 23(2), 1998, pp. 242-266.

29. Quinn, J.B., Anderson, P., and Finkelstein, S., Managing Professional Intellect: Making the Most of the Best, Harvard Business Review, 1996, pp. 71-80.

30. Damanpour, F., Organizational Innovation: A Meta-analysis of Effects of Determinants and Moderators, Academy of Management Journal, 34(3), 1991, pp. 555-590.

31. Kanevsky, V., and Housel, T., The LearningKnowledge-Value Cycle, Knowing Firms: Understanding, Managing and Measuring Knowledge, Sage Publications, London, 1998.

32. Leonard-Barton, D., Wellsprings of Knowledge: Building and Sustaining the Sources of Innovation, Boston, MA, Harvard Business School Press, 1995.

33. Madhavan, P., and Anol, B., Understanding Post-Adoption Behavior in the Context of Online Services, Journal of Information Systems Research, 9(4), 1998, pp. 362-379.

34. Caruana, A., Morris, M.H., and Vella, A.J., The Effect of Centralization and Formalization on Entrepreneurship in Export Firms, Journal of Small Business Management, 36(1), 1998, pp. 16-29.

Appendix 1. Operationalisation of research variables
35. Graham, J., and Gibson, K., The End of Capitalism (As We Knew It): A Feminist Critique of Political Economy, Blackwell Publishers, Oxford, U.K., 1996.

36. Woodman, R.W., Sawyer, J.E., and Griffin, R.W., Toward a Theory of Organizational Creativity, Academy of Management Review, 18(2), 1993, pp. 293-321.

37. Stonehouse, G.H., and Pemberton, J.D., Learning and Knowledge Management in the Intelligent Organisation, Participation and Empowerment: An International Journal, 7(5), 1999, pp. 131-144.

38. Hopper, M.D., Rattling SABRE-new Ways to Compete on Information, Harvard Business Review, 68(4), 1990, pp. 118-125.

39. Bennett, R., and Gabriel, H., Organisational Factors and Knowledge Management within Large Marketing Departments: An Empirical Study, Journal of Knowledge Management, 3(3), 1999, pp. 212-225.

40. Jarvenpaa, S.L., and Staples, D.S., The Use of Collaborative Electronic Media for Information Sharing: An Exploratory Study of Determinants, Strategic Information Systems, 9, 2000, pp. 129-154.

41. Redman, T.C., The Impact of Poor Data Quality on the Typical Enterprise, Communications of the ACM, 41(2), 1998, pp. 79-82.

42. Wixom, B.H., and Watson, H.J., An Empirical Investigation of the Factors Affecting Data Warehousing Success, MIS Quarterly, 25, 2001, pp. 17-41.

43. Kettinger, J., and Lee, C., Perceived Service Quality and User Satisfaction with the Information Services Function, Decision Sciences, 25(56), 1994, pp.737-766.

44. Gelderman, T., The Relation between User Satisfaction, Usage of Information Systems, and Performance, Information \& Management, 34(1), 1998, pp.11-18.

\begin{tabular}{|c|c|c|}
\hline $\begin{array}{l}\text { Variable } \\
\text { (references) }\end{array}$ & Operational definition & Measures \\
\hline $\begin{array}{l}\text { IS quality } \\
\text { (Palvia et al., [2], } \\
\text { Delone \& McLean, } \\
\text { [3]) }\end{array}$ & $\begin{array}{l}\text { The degree to which IS can } 1 \\
\text { support the individual users } \\
\text { in executing business } \\
\text { processes in an organisation } 2 \\
\text { (Palvia et al., [2]). } \\
\\
5 \\
6 \\
7 \\
8 \\
9\end{array}$ & $\begin{array}{l}\text { 1. The IT personnel assigned to provide support for the use and } \\
\text { maintenance of information systems that I use has a very good } \\
\text { technical ability } \\
\text { 2. Information system that I use is very user friendly and easy to use } \\
\text { 3. Information system application that I use in my work provides } \\
\text { precisely the information I need } \\
\text { 4. Information systems application that I use provides enough } \\
\text { information for me to do my work } \\
\text { 5. The information system provides data to speed up decision-making in } \\
\text { my work } \\
\text { 6. Information provided by the system makes executing my job much } \\
\text { easier } \\
\text { 7. I feel the information system is useful for my job } \\
\text { 8. I am satisfied with the functionalities provided in the IS application } \\
\text { 9. When there is a problem in the IS application that I use, I can easily } \\
\text { get help from the existing IT staffs }\end{array}$ \\
\hline
\end{tabular}




\begin{tabular}{|c|c|c|}
\hline $\begin{array}{l}\text { Variable } \\
\text { (references) }\end{array}$ & Operational definition & Measures \\
\hline $\begin{array}{l}\text { Individual Benefits } \\
\text { (Shang \& Seddon, }\end{array}$ & $\begin{array}{l}\text { Individual benefits derived } \\
\text { from the use of information }\end{array}$ & $\begin{array}{l}\text { 1. After using the information system, I have a better understanding of } \\
\text { the business processes, including an understanding of the processes } \\
\text { that are outside of my work area }\end{array}$ \\
\hline
\end{tabular}
[13])

Collaboration
(Lee \& Choi, [12])

The degree to which

2. After using the information system, I have more knowledge and skill which is useful for my work

3. After using the information system, I became motivated to better understand the "process" that occurs in the company, and not just the "results"

4. After using the information system, the time needed to learn something becomes shorter

5. After using the information system, I became more responsible in completing my work

6. After using the information system, I became more proactive in solving a problem.

7. After using the information system, my authority in carrying out the work is increased

8. After using the information system, my involvement in business activities of the company is increased

9. After using the information system, I became more focused on our customers

10. After using the information system, I became more focused on my work

11. After using the information system, I became more concerned with my performance

12. After using the information system, I became more satisfied with my work because making decisions becomes easier

13. After using the information system, my job satisfaction is increased as information system improves the efficiency of my work

14. After using the information system, my job satisfaction is increased as information system increases my knowledge

15. After using the information system, my job satisfaction is increased because of the possibility of fraud is reduced

16. After using the information system, my job satisfaction is increased as information systems increases the transparency in the company

(Lee \& Choi, [12]) individuals in the group cooperation in his/her unit

actively assist each other in 2. Support among members of the organisation

completing the work $\quad 3$. Voluntary help among members of the organisation

(Hurley \& Hult, [23]) 4. Willingness to cooperate with colleagues, including colleagues from other units within the company

\begin{tabular}{ll}
\hline Trust & Level of trust in the \\
(Lee \& Choi, [12]) & behavior, intent, and
\end{tabular}

capabilities of others

1. In general members of this company can be trusted

2. I trust in the good intentions and behavior of my co-workers

(Kreitner \& Kinicki, [26])

3. I have confidence in the ability (skill) of my colleagues

4. Belief that colleagues will work with the behavior expected according to the company's values

5. Belief that every decision made by a co-worker is good for the company's interests and not for their own sake

6. The organisation establishes a relationship based on mutual trust between members

Learning

(Lee \& Choi, [12])
The level of support to learn 1 . and grow within the organisation (Hurley \& Hult, [23])
The company provides a variety of training programs for the improvement of the performance of the employees

2. The company provides its employees with development opportunities

3. The Company provides support and opportunities for employees to attend seminars, symposia, etc.

4. In the company, there are a variety of both formal and informal gatherings for employees to exchange ideas and information 


\begin{tabular}{|c|c|c|}
\hline $\begin{array}{l}\text { Variable } \\
\text { (references) }\end{array}$ & Operational definition & Measures \\
\hline $\begin{array}{l}\text { Expertise } \\
\text { (Lee \& Choi, [12]) }\end{array}$ & $\begin{array}{l}\text { The level of skill and } \\
\text { understanding of } \\
\text { individuals regarding his } \\
\text { work and others' works in } \\
\text { the company (Leonard, [32]) }\end{array}$ & $\begin{array}{l}\text { 1. I understand not only their own field of work but also some other work } \\
\text { colleagues } \\
\text { 2. I am able to provide input or consideration to the work of other } \\
\text { colleagues } \\
\text { 3. I communicate well not only with colleagues but also with the } \\
\text { department from other departments colleague } \\
\text { 4. I have skills needed for executing my works } \\
\text { 5. I have the ability to do the job effectively without being distracted by } \\
\text { the changes in my work environment }\end{array}$ \\
\hline $\begin{array}{l}\text { Centralisation } \\
\text { (Lee \& Choi, [12]) }\end{array}$ & $\begin{array}{l}\text { Level of authority and } \\
\text { control by individuals in the } \\
\text { organisation regarding the } \\
\text { decision he made (Caruana } \\
\text { et al, [34]) }\end{array}$ & $\begin{array}{l}\text { 1. In carrying out the work, members of the organisation can take action } \\
\text { without the guidance of their supervisor } \\
\text { 2. In carrying out the work, members of the organisation are encouraged } \\
\text { to make their own decisions } \\
\text { 3. In carrying out the work, members of the organisation do not need to } \\
\text { leave the decision to others } \\
\text { 4. In carrying out the work, members of the organisation do not need to } \\
\text { ask a supervisor before acting or making a decision } \\
\text { 5. In carrying out the work, member organisations can make their own } \\
\text { decisions without always obtain prior approval from the employer or } \\
\text { other person within the company. }\end{array}$ \\
\hline $\begin{array}{l}\text { Formalisation } \\
\text { (Lee \& Choi, [12]) }\end{array}$ & $\begin{array}{l}\text { The degree to which any } \\
\text { decision made or anything } \\
\text { related to the job is clearly } \\
\text { regulated by formal rules, } \\
\text { legal standards, and } \\
\text { procedures (Holsapple \& } \\
\text { Joshi, [18]) }\end{array}$ & $\begin{array}{l}\text { 1. There are several activities in work that is not clearly regulated by } \\
\text { formal procedures } \\
\text { 2. Any contact or relationship regarding the work should be formal or } \\
\text { well planned } \\
\text { 3. There are clear regulations and legal standards for all activities within } \\
\text { the organisation } \\
\text { 4. sometimes rules can be ignored and work is informally approved for a } \\
\text { particular situation }\end{array}$ \\
\hline
\end{tabular}

